Haủssmann, Ửeber die erste Beobachtung von Cysten der Scheide. 533

Unser Fall ist insofern bemerkenswerth, als die Frau sich nie geschnüt hat und als ihre Krankheit erst 10 Jahre nach ihrer ersten Entbindung bemerkt worden ist. Ueber die Ursache derselben ist von sorgfältigen Sectionen eine mehr positive Antwort zu erwarten, vorläufig aber mit. Leopold und Meissner "Mesohepar" als disponirende Ursache, und Verminderung der Elasticität der Bauchwände und des Diaphragma und harte mechanische Arbeit als Gelegenheitsursachen anzunehmen.

\title{
Ueber die erste Beobachtung von Cysten der Scheide.
}

\author{
Geschichtliche Bemerkung \\ ron
}

Dr. Haussmann

in Berlin.

Im zweiten Bande dieses Archives (S. 383) giebt Winckel an, dass nach Stafford Lee die Cysten der Scheide zuerst von Sir Astley Cooper erwähnt worden sind, dass er selbst jedoch die erste Bemerkung über sie bei Okley $\mathrm{Heming}$ (1831) entdeckt habe. Da sich alle mir bekannt geworderien späteren Schriftsteller auf diese geschichtliche Darstellung berufen, so dürfte eine kleine Vervollständigung derselben nicht überflüssig erscheinen.

Als ich vor Kurzem wegen eines anderen Zweckes Haller's grosses Werk über die Physiologie des menschlichen Körpers nachschlug, stiess ich auf die folgende Stelle (Elementa physiologiae corporis humani, Tomus VII. Bernae 1765. Liber XXVIII, sect. II. $\$$ XVIII. S. 77): "Glandulas vaginae veras, rotundas, varii $\mathrm{Cl}$. viri repererunt, etiam depinxerunt, in brutis frequentiores; tamen etiam in homine visas.

Eas non reperi, etsi hydatides in vagina vidi, et rejecit Ill. Morgagni (advers. IV. S. 45)."

Da, wie zahllose Stellen der Anatomen und Kliniker des vorigen Jahrhunderts beweisen, das Wort, hydatides" von ihnen zur Bezeichnung eines mit Flüssigkeit gefiillten, mehr weniger diunnwanäigen Sackes gebraucht worden ist, ja nicht selten noch jetzt in die 
sem Sinne angewendet wird, so gebührt Haller das Verdienst, exheblich früher, als Okley Heming und selbst Astley Cooper die Cysten der Scheide gesehen zu haben, indess kann nach dem von dem berihtmten Bibliographen gewählten Wortlante wohl kaum ein Zweifel darüber obwalten, dass er sich einer anderen Ausdrucksweise bedient hätte, wenn die Cysten der Scheide au seiner Zeit nicht schon anderweitig bekannt gewesen wären.

Berlin, im Juli 1875.

\section{Verhandlungen der gynäkologischen Section der Natur- forscherversammlung in Graz 1875. ${ }^{1}$ )}

\section{Erste Sitzung.}

Vorsitzender: Professor von Helly.

Ständige Secretäre: DDr. Zechner und Reibmayr.

Dr. Ahlfeld (Leipzig): Ueber die Persistenz des Dotterganges in der Nabelschnur reifer Frächte.

Ueber den Verbleib der Reste des Dotterstranges innerhalb der Nabelschnur hat man sich bisher die verschiedensten Vorstellungen gemacht. Einige, unter ihnen Förster, geben an, der Dotterstrang ginge in der Nabelschnur ganz verloren; Schultze hat ihn in mehreren Fällen gefunden. Leider hat Sehultze seine Untersuchungen an getrockneten Nabelschnüren gemacht und aus diesem Grunde keine günstigen Bilder bekommen. - Um ïber das Verhalten des Dotterstranges Aufschluss zu bekommen, habe ich Querschnitte von Nabelschnüren gemacht, die frisch in Müller'sche Lösung und später in Spiritus gelegt" worden waren.

Die Untersuchungen sind an den Nabelschnüren 1. reifer wohlgestalteter Früchte, 2. frühreifer und unreifer wohlgestalteter Früchte, 3. missgebildeter und kranker Friichte, 4 . von $Z$ willingen, Drillingen u. s. w., 5. bei abnorm entwickelten Eitheilen angestellt worden.

1) Das Referat ist theilweise dem Tageblatte entuommen, theilweise nach Anfzeichnungen des Referenten zusammengestellt. 